ORIGINAL ARTICLE

\title{
The coordination abilities development in female students based on
} dance exercises

\author{
Olga V. Limanskaya ${ }^{1 \mathrm{ABCDE}}$, Olena V. Yefimova ${ }^{1 \mathrm{ABCDE}}$, Irina V. Kriventsova ${ }^{1 \mathrm{ACDE}}, \mathrm{Krzysztof} \mathrm{Wnorowski}^{2 \mathrm{CDE}}$, \\ Abdelkrim Bensbaa ${ }^{3 \mathrm{CDE}}$ \\ ${ }^{1}$ H.S. Skovoroda Kharkiv National Pedagogical University, Ukraine \\ ${ }^{2}$ Gdansk University of Physical Education and Sport, Poland \\ ${ }^{3}$ Military Center of Sport Training, United Arab Emirates
}

Authors' Contribution: A - Study design; B - Data collection; C - Statistical analysis; D - Manuscript Preparation; E - Funds Collection.

\begin{abstract}
Background The physical fitness of students is characterized by the level of their abilities development to perform and Study Aim movements of varying complexity. One of the important components in the system of movements is coordination skills. The aim of the study is to identify the level of special and general coordination of students majoring in "Choreography" and provide recommendations for the development of coordination skills in the process of studying modern-jazz dance.

Material and The study involved students of the first and second year of study $(n=10$, at the beginning of the study Methods (1 year) age - $17.4 \pm 0.7$ years) majoring in "Choreography". Tests were used to determine the level of development of general and special coordination skills. The level of coordination readiness at the beginning of training and after three semesters of training was determined. The study was conducted over three semesters (September 2019 - December 2020). Curricula for students' training do not include the discipline "Physical Education". The development of physical qualities is the task of special subjects in the course of professional training: 16 hours per week. The workload of students in modern-jazz dance was 2 hours a week. Forms of study for a certain period - full-time (70\%), online learning (10\%), mixed (20\%). In September 2019 and in December 2020, the same students passed selected tests.

Results: $\quad$ The following significant changes in increasing the coordination level of the abilities were determined: to control temporal and spatial factors of movements; coordination of movements in combination; vestibular stability; musical-rhythmic coordination $(p<0.01)$. The proposed technique assumes that at the first stage of studying modern jazz dance two, three, four centers are coordinated in simultaneous parallel movement.

Conclusions: The need to improve the curriculum of modern jazz dance, the introduction of additional courses to the educational program in the major "Choreography". The technical and lexical base of modern jazz dance in combination with special physical training provides opportunities for the coordination skills development in choreographers.

Keywords: $\quad$ physical fitness, choreography, professional training, professional disciplines, teacher.
\end{abstract}

\section{Terminology [1]}

Bounce: Principle of execution of movements, characterized by mobility, especially of the gluteal and hamstring muscles in a way that resembles bouncing while keeping the feet on the ground.

Sauté: Is a classical ballet term that can be used alone or with another term to mean the step is performed while jumping.

Plie: Bent, bending. A bending of the knee or knees. This is an exercise to render the joints and muscles soft and pliable and the tendons flexible and elastic, and to develop a sense of balance.

Temps sauté: This can be executed with both feet from first, second, third, fourth, or fifth position starting with a demi-plié, leading to a jump in the air that lands with the feet in the same position as they started.

Contraction: A contracting of the abdominal muscles

\footnotetext{
(c) Olga V. Limanskaya, Olena V. Yefimova, Irina V. Kriventsova,

Krzysztof Wnorowski, Abdelkrim Bensbaa, 2021

doi:10.15561/20755279.2021.0406
}

so the lower spine becomes rounded and the abdominal area hollowed out. The shoulders remain directly above the hips.

Arch: Position in which the whole or upper body is extended, creating the form of an arch.

Point Ta flex: Straightened state of body parts. To bend slightly or relax a portion of the body.

Pas chaine: In dance it is a two-step turn which can be performed in plie or releve. The body rotates 180 degrees on each step.

Swinging movements: A movement quality that is characterized by a reaction to the force of gravity. A lifted body part releases and drops along a curved path. Energy is added to the momentum of the drop to carry the body part upward on an arc where it suspends before returning on a downward path.

Modern-jazz dance: Modern-jazz dance is a term used in the academic dance world. It refers to a modern style that combines ballet technique with elements of contemporary and African - derived dances. 


\section{Introduction}

The physical fitness of students is characterized by the level of development of their abilities to perform movements of varying complexity. One of the important components in the system of movements is coordination skills. Their development requires considering the level of general physical fitness of students. The purpose of developing coordination skills can be: to improve or maintain health at the appropriate level; raising the level of mastery of movements to the standards of the future profession. It is professional standards that determine the approaches to the development of students' coordination skills. Therefore, for students majoring in "Choreography" an important component of professional development is the level of coordination skills development.

Problems of coordination abilities development are profoundly presented in researches of various directions. Bernstein emphasized that coordination is the overcoming of excessive degrees of freedom of the organs of movement and their transformation into controlled systems [2]. Matveev defines coordination abilities as the ability to appropriately coordinate movements in the construction and reproduction of new movements [3].

Logan et al. analyzed research on the problems of fundamental motor skills (FMS) [4]. The authors recommend it because FMS are the "building blocks" of more advanced, complex movements.

Opportunities and effectiveness of the students' coordination skills development depend on their previous training at school. Marchenko and Bezpalko studied the method of complex control of coordination abilities in 7-year-old boys [5]. It is determined that the development of coordination skills is an important part of the educational process in school. The lessons at school create the basis for new motor skills. This is a prerequisite for the successful development of other motor skills.

Boutios et al. studied the skills of movements coordination in children engaged in taekwondo [6]. The authors found out that coordination indicators improve with age and are positively affected by sports. Other studies have shown that the level of coordination indicators development is closely correlated with the effectiveness of competitive activities in volleyball [7] and handball [8].

In the physical training programs of students, it is necessary to consider the initial level of their coordination training. Barylko studied the dynamics of the coordination abilities level in students of I-II years of study [9]. It is established that it is possible to classify students according to the level of coordination preparedness according to their age. This is of practical importance for the development of effective physical education programs for students. Chien et al. investigated the role of errors in teaching motor skills of students [10]. The authors propose a scheme in teaching motor skills, which gives teachers a basis for its implementation by students.

The subjects of professional training in higher educational institutions of choreographic direction are the basis for the acquisition of professional skills of dancers [11]. This requires the future teacher to master a high level of dance movements. Nyberg et al. investigated the problems of showing motor exercises by a teacher during dance games [12]. The authors emphasized the teacher's ability to move as an integral educational goal of a physical education lesson.

Coordination is an important component of training in the art of dance. Vaganova notes that the achievement of full coordination of all movements of the human body forces to inspire the movement of thought, meaning, $\operatorname{mood}[13]$.

Another study examined a model of sports dance training based on flexibility and coordination [14]. The authors found that the development of a special training regime for sports dance based on flexibility and coordination should correspond to the physical condition of students.

Busol et al. studied stage movement in the acting profession [15]. The authors define coordination as the basis of agility and recommend approaches to its development. This is a guarantee of the optimal ratio of time and energy during the performance of the actor's movement on the stage.

$\mathrm{Ou}$ Tsin studied the development of masters' coordination skills through the means of "contemporary" dance. The author emphasizes the peculiarities of choreographic coordination in the coherence of movement, music, and artistry in a single time-space [16].

The works of specialists in rhythmic gymnastics deserve special attention $[17,18]$. This complex coordination sport is very close to modern choreography.

The art of dance in schools and the corresponding training of students in physical education classes have been studied in several areas.

Orbaek et al. studied the experience of student teachers from teaching creative dance in their practical physical education classes in Norwegian schools [19]. The authors recommend introducing creative dance as a subject in school education.

Other authors studied dance-based physical education programs based on students' creative abilities [20]. This study provides additional support for the place of dance and creativity in the physical education curriculum.

Other authors agree with this statement. Amado et al. confirmed that schools should focus on encouraging teachers to teach motivational strategies to develop students' adaptive behavior [21]. This will develop a motivational style during dance classes at school.

Another study demonstrates that there is no aesthetic view on movement in physical education and research tasks for learning are rare [22]. It is confirmed that expressive dance tasks are well suited for the research method of teaching. This interaction can challenge the existing logic of competition and ranking in physical culture.

The next study focused on understanding the experience of undergraduate students in gymnastics and dance education in the context of modular education in 
higher education [23]. The authors concluded that the opacity and transparency of the person can be important in student life's development.

Gibbs et al. investigated different ways of using dance exercises to teach dance in high school physical education [24]. It is confirmed that dance exercises can be used from a pedagogical point of view to teach dance. This allows the teacher to focus on observing, supporting, assigning tasks and providing feedback.

Another study recommends paying special attention to the knowledge of dance and pedagogical content in student training programs [25].

There is a lot of information about coordination and a sense of rhythm in research on the art of choreography. The types of coordination that are necessary to perform the elements of modern dance have not been sufficiently studied. There is an obvious need to conduct research considering the level of general and special physical training of students. Thus, the main task of the study is to develop a methodology for the development of the physical qualities of dancers. In particular, methods of development and improvement of their coordination skills.

The purpose of the study is to identify the level of special and general coordination of students majoring in "Choreography" and provide recommendations for the development of coordination skills in the process of studying modern jazz dance.

\section{Material and Methods}

Participants.

The study involved students of the first or second year of study $(n=10)$, majority "Choreography". At the beginning of the study, the average age of participants was $17.4 \pm 0.7$ years.

The study was conducted following the World Medical Association Declaration of Helsinki [26] and approved by the ethics committee of H. S. Skovoroda Kharkiv National Pedagogical University (Ukraine).

Research Design.

The study was conducted over three semesters (September 2019 - December 2020). Curricula for student training do not include the discipline "Physical Education". The development of physical qualities is the task of special subjects in the course of professional training: 16 hours per week. The workload of students in modern dance was 2 hours a week. Forms of study for a certain period - full-time $(70 \%)$, online learning (10\%), mixed (20\%). In September 2019 and in December 2020, the same students passed selected tests.

Information on the individual physical fitness of female students was collected and summarized. A program for coordination skills development by means of modern jazz dance has also been designed.

Tests were chosen to determine the condition of coordination abilities.

Test №1. 4x9 m Shuttle test, s. - determination of the ability to control temporal, spatial factors of movements.

Test № 2. "Static equilibrium test according to Bondrevskij method with closed eyes, s" [27] determination of the ability to maintain balance.

The author's tests include exercises for forced swing movements of modern jazz dance; performing turns on two legs with a stop in position; exercises for coordination on the principle of "control".

Test №3. "Test for performing forced swing movements of modern jazz dance" - determining the ability to coordinate movements in one combination.

\section{Description:}

- Starting position - the second position of the legs, hands over the body.

- On one hands go up. The knees perform "Bounce" (free swing). At the same time the hands, head, body turn to the right. Then the hands go down, the legs straighten.

- On two hands go up. The knees perform "Bounce" (free swing). At the same time the hands, head, body turn to the left. Then the hands go down, the legs straighten.

- On three hands go up. The knees perform "Bounce" (free swing). At the same time the hands, head, body turn to the right. Then the hands go down, and the jump saute is performed in the second position.

- On four hands go up. The knees perform "Bounce" (free swing). At the same time the hands, head, body turn to the left. Then the hands go down, and the legs jump sauté legs in the second parallel position. Return to the starting position.

Note: in swinging hands together with the body, pay attention to the exact return to the starting position from which the swinging begins. The head is not put back. The knees perform "bounce", not a muscular plié. The arms are free, but not completely relaxed. Their natural form is kept, ie "included in the work". Landing after the jump is soft, without touching the floor with your heels, feet free. Bending at the knees performs exactly in the direction of the toes.

The test is performed using the display method. The teacher shows the exercise 2 times in slow motion, then 1 time in medium and 1 time in fast. Then students are given 7 minutes for self-training. For control performance students were divided into subgroups according to the list - 1 group - 5 people, 2 group - 5 people.

Evaluation: on a 5-point system:

- "5" - for accurate and correct execution of the sequence and the movements themselves;

- "4" - for insufficiently accurate execution of individual elements;

- " 3 " - for mistakes in the sequence of movements;

- "2-1" - for significant mistakes in the execution of movements and their sequence.

The test is not credited if the student cannot complete the combination at all.

Test № 4. "Performing turns on two legs with a stop in the 4th position" - determination of vestibular stability.

Description: At the teacher's command, the student performs 3 turns on both legs with the right foot, hands over the body, then stop in 4 th free position: right leg in 
front on the toes, left leg bent at the knee. A left hand raises upward.

Note: turns must be performed on one line, during the stop in the 4th position the body should be kept still.

Evaluation: on a 5-point system:

- "5" - accurate and correct execution of turns on one line, a clear stop;

- "4" - insufficiently accurate execution of turns, but a clear stop;

- "3" - non-compliance with one line during turns, not a clear stop;

- "2-1" - significant mistakes in the execution of turns, not a clear stop. The test is not credited if the student cannot complete the combination at all.

Test № 5. "Exercise for coordination on the principle of "control"- determining the ability to musical-rhythmic coordination.

Description: female students were divided into 2 subgroups as in test №3. The exercise was performed in 3 stages: the first time at a slow motion, the second time at a medium motion, the third time at a fast motion.

Evaluation: on a 5-point system:

- "5" - accurate and correct performance of movements according to the rhythmic pattern of musical accompaniment;

- "4" - insufficiently accurate performance of individual elements and correct performance of movements according to the rhythmic pattern of musical accompaniment;

- "3" - mistakes in the performance of movements and non-compliance with the rhythmic pattern;

- "2-1" - significant mistakes in the performance of movements and lack of sense of rhythm. The test is not credited if the student cannot complete the combination at all.

Students majoring in "Choreography" from the first semester master the technique of modern dance movements for 2 hours per week. However, the technique of modern jazz dance performing is introduced only after acquiring certain complex motor skills. In classes on the subject "Theory and methods of teaching modern dance" students participated in the preparation of choreographic compositions for performances of the dance ensemble ( 2 hours 2 times a week). Distance learning took place in the period from March 13 to May 29, 2020, and from October 15 to November 20, 2020. The peculiarities of the university's work during the COVID-19 pandemic provided an opportunity to conduct classes in a mixed form. For the period of online learning, students were offered the following tasks:

1. Make videos of warm-up combinations (plié, bt. tendu, bt. tendu jete);

2. Make videos of cross-turn combinations;

3. Make a complex for stretching muscles;

4. Make a report on the topic "Creativity of Martha Graham".

A method of the coordination abilities development in future choreographers was developed. The purpose of this approach is to try to increase the level of mastery of complex movements of modern jazz dance and professional skills.

At the first stage, paired rhythms were used in musical accompaniment: $2 / 4,4 / 4,6 / 8$. Gradually moved to a polyrhythm of a more complex level: odd rhythms: $5 / 4$, $7 / 8,9 / 8$; introduction of complex rhythmic patterns. The structure of the training is shown in Table 1.

It should be noted that paragraphs 2-5 (Table 1) were changed by:

\section{Change combinations:}

2. Parterre. Starting position - "Star"; pass to the position of "embryo"; then the "embryo" sitting position. Position sitting on bent knees, back straight. Move to the position of the legs forward (as a fold, the body is flat), the body bends freely to the side, the legs swing in the ring.

3. Cross (steps, jumps, turns). Adding and transforming the jump temps sauté:

1. To perform in parallel positions.

2. To start from the reverse position, and during landing move the feet to a parallel position.

3. During the jump, bend your knees, put your shin back and touch your buttocks with your heels.

4. To bend one leg during the jump to the "knee" position.

5. To perform a contraction to the center of the body during the jump.

6. At flight, perform arch of body.

7. To bend both knees and join the feet ("frog").

8. To spread straight legs apart.

9. To bend your knee to the chest.

4. Dance composition (study of combinations). Starting position - legs in the first parallel position, hands over the body. Triplet. (Tombe right leg forward, simultaneously straightens and rises to the first position of the left hand, the right hand is moved to the second position. Two steps on the toes of the left and right foot, hands down and swing over the body).

5. Cooldown. Introduction of sphinx poses, plow; bending to straight legs (feet point and flex).

The proposed method assumes that at the first stage of modern jazz dance studying two, three, four centers are coordinated in simultaneous parallel movement. The process of studying coordination is created from simple to complex. First, there is an explanation of how to distribute attention between the movement of the two centers. For example, one of the centers may be in a swing. Then it does not need attention but needs to focus on the movement of another center.

Statistical analysis.

The statistical analysis program SPSS 20 was used. For each variable was calculated: $\mathrm{X}$ - arithmetic mean; $\mathrm{s}$ - is the standard deviation; $\Delta \mathrm{x}$ - is the marginal sampling error for the mean; $t$-Student's criterion; $p$ - is the level of significance. The significance of differences in the groups was assessed using parametric indicators (Student's test) and nonparametric indicators (Wilkinson-Mann-Whitney, Rosenbaum tests). 
Table 1. The tasks structure of three semesters performance by students

\begin{tabular}{|c|c|c|c|}
\hline No & Type of work & Duration & Content \\
\hline 1 & Warm up & $\begin{array}{l}15-20 \\
\min \end{array}$ & $\begin{array}{l}\text { It begins with the use of various forms of pore de bra, including swings, } \\
\text { spirals, small slides, turns. Then pass to the traditional lesson plie, bt. } \\
\text { tendu, bt. tendu jete, rond, adajio, grand battement (in parallel and } \\
\text { inverted positions with the work of the body, head arch, drop, baunce- } \\
\text { rebounce, releve). To these combinations are added: swing, pulses, } \\
\text { deviations from the axis, twisting, small parterre motions, falls. }\end{array}$ \\
\hline & & & $\begin{array}{l}\text { This part of the lesson is used to solve the following tasks: exercises to } \\
\text { prepare and perform stunts and falls; performing acrobatic elements. }\end{array}$ \\
\hline 2 & Parterre & $15 \mathrm{~min}$ & $\begin{array}{l}\text { The parterre consists of the following elements: fall; «book»; «Flight» - } \\
\text { rolling through the shoulder blades; swing in the parterre; overturning, } \\
\text { over the shoulder back; stand on the shoulder. }\end{array}$ \\
\hline 3 & $\begin{array}{l}\text { Cross (steps, jumps, } \\
\text { turns) }\end{array}$ & $15 \mathrm{~min}$ & $\begin{array}{l}\text { In this part of the lesson were used: steps in a jazz manner; steps with } \\
\text { animation (triplet); study of slide steps; performance of crosses with } \\
\text { jumps of classical dance jete, sisson; crosses with swing (tour, shene) in } \\
\text { large poses. }\end{array}$ \\
\hline \multirow{4}{*}{4} & \multirow{4}{*}{$\begin{array}{l}\text { Dance composition } \\
\text { (study of } \\
\text { combinations) }\end{array}$} & \multirow{4}{*}{$\begin{array}{l}20-25 \\
\min \end{array}$} & $\begin{array}{l}\text { 1. Combination using bends, body spirals, contraction and realise. At } \\
\text { the same time the «working» leg is raised by } 90 \text { degrees and above. }\end{array}$ \\
\hline & & & $\begin{array}{l}\text { 2. Combination with the use of tour lent and other types of parterre } \\
\text { tours, fouette en tournant and pirouettes. }\end{array}$ \\
\hline & & & $\begin{array}{l}\text { 3. Combination with the use of different angles, level changes, moved } \\
\text { around the classroom space. }\end{array}$ \\
\hline & & & $\begin{array}{l}\text { Combinations are formed into a dance composition considering the } \\
\text { passed material and individual features of students. }\end{array}$ \\
\hline 5 & Cooldown & $5 \min$ & $\begin{array}{l}\text { Stretching exercises on the parterre (fold, butterfly, twine, pulsating } \\
\text { body bends, the leg opening with hands). Use of yoga poses } \\
\text { (downward-facing dog pose; cobra pose; bow pose; stretching pose). }\end{array}$ \\
\hline
\end{tabular}

Table 2. Dynamics of coordination readiness indicators of female students

\begin{tabular}{|c|c|c|c|c|}
\hline \multirow[b]{2}{*}{ № } & \multirow[b]{2}{*}{ Tests } & \multicolumn{3}{|c|}{ Female students $(n=10)$} \\
\hline & & $\begin{array}{l}\text { The beginning of the } \\
\text { experiment }\end{array}$ & $\begin{array}{l}\text { The end of } \\
\text { experiment }\end{array}$ & $\mathbf{p}$ \\
\hline 1. & Test $1.4 \times 9 \mathrm{~m}$ Shuttle test, s. & $11.17 \pm 0.39$ & $10.95 \pm 0.41^{*}$ & $0.00025<0.01$ \\
\hline \multirow[t]{4}{*}{2.} & $\begin{array}{l}\text { Test 2. Static balance according to the } \\
\text { Bondrevskij method, s. : }\end{array}$ & & & \\
\hline & Stand on the right leg, s. & $4.6 \pm 2.32$ & $5.2 \pm 2.68 *$ & $0.04<0.05$ \\
\hline & Stand on the left leg, s. & $4.9 \pm 1.52$ & $5,4 \pm 1,52 *$ & $0.026<0.05$ \\
\hline & Among the best indicators, s. & $6 \pm 1.8$ & $7 \pm 1.8^{*}$ & $0.0042<0.01$ \\
\hline 3. & $\begin{array}{l}\text { Test 3. Performing forced swing } \\
\text { movements of modern jazz dance }\end{array}$ & $2.6 \pm 0.72$ & $3.4 \pm 0.8^{*}$ & $0.0015<0.01$ \\
\hline 4. & $\begin{array}{l}\text { Test } 4 \text {. Performing turns on two legs } \\
\text { with a stop in the } 4 \text { th position }\end{array}$ & $3.2 \pm 0.68$ & $4 \pm 0.8^{*}$ & $0.0015<0.01$ \\
\hline 5. & $\begin{array}{l}\text { Test 5. Exercise for coordination on } \\
\text { the principle of «control» }\end{array}$ & $2.9 \pm 0.54$ & $3.7 \pm 0.7 *$ & $0.0015<0.01$ \\
\hline
\end{tabular}

* - differences are significant according to Student's t-test

\section{Results}

It was determined that at the beginning of the study, the majority of female students showed low and medium scores on all tests. At the end of the study, there were positive changes in all test indicators. The results of coordination training in the dynamics of three semesters are presented in Table 2 .
The results of the study showed significant changes: in the ability to manage temporal and spatial factors; coordination of movements in a single combination, vestibular stability, musical-rhythmic coordination $(p<0.01)$. There was an increase in the average statistical indicators for maintaining balance $(\mathrm{p}<0.05)$.

There is a tendency to increase coordination skills. 
As a result, there is an expansion of the arsenal of motor capabilities and faster assimilation of educational material.

\section{Discussion}

Our research was aimed at determining the level of special and general coordination of future choreographers. In choreography, it is accepted to distinguish: coordination, aplomb, sense of rhythm. The results obtained generally confirm the opinion of other researchers [2, 3, 28]. The authors noted that coordination abilities depend on the characteristics of the central nervous system, its physiological conditions, and the restructuring of individual muscles and the whole body. The effectiveness of constant monitoring of choreographers' physical fitness is proved and is emphasized in our previous work [11].

The analysis of other studies on the development of coordination skills and dance structure of motor actions allows us to mainly and partially agree with their authors [29-31]. The authors noted that coordination in modern jazz dance is performed out in two ways: by impulse (two or more centers are moved simultaneously) or by the principle of control (centers have joined the movement sequentially). Jazz-modern dance combines elements of jazz choreography; modern style and classical dance technique; expression and complex emotions. Different centers can coordinate. For example head and shoulders, hands and head, shoulders and head, etc.

In general, we agree with the opinion of researchers Nikitin [32] and Kolumbet [28] on the classification of coordination skills development. However, we det6ermined the following components of specific coordination in modern jazz dance:

Ability to balance - maintaining the stability of posture (balance) in certain static positions of the body during the movement (body bend movements, flat back or tabletop, Deep body bend, which are used throughout the lesson in the "warm-up", "Adagio", " Parterre "and" Cross ").

Ability to musical-rhythmic coordination (sense of rhythm) - the ability to coordinate a given movement with music rhythm and image. The student hears the rhythm and can clap or perform exercises according to the musical accompaniment.

Ability to restructure motor actions - the speed of transformation of the performed forms of movements or switching from one motor action to another in changing conditions (cross combinations, etc.).

Vestibular stability - the ability to accurately and stably perform motor actions in conditions of vestibular stimuli (overturns, throws, turns, etc.).

Arbitrary muscle relaxation - the ability to optimally balance the relaxation and contraction of certain muscles at the given time (Roll down and roll up, drop, swing, etc.).

The ability to coordinate movements - the combination of individual movements and actions into integral combinations.

We agree with Hua [14] on the development of a special training regime for sport dance for students.
However, we propose to create it considering the sets of exercises for all physical skills development and with an emphasis on the implementation of complex coordination exercises.

The most difficult test for students was the Bondrevskij test with closed eyes. That is why we emphasize the need to perform dance elements with closed eyes in class and suggest the use of elements of ideomotor training.

\section{Conclusions}

Professional coordination abilities of dancers are readiness for optimal control of separate specific tasks: on maintenance of vestibular balance; ability to react quickly; muscle relaxation; orientation in time and space; possibility to restructure the rhythmic scheme; ability to work in harmony with all parts of the body. The main principles of the methodology of coordination abilities development in choreographers are the principles of individualization and differentiation. It is recommended to pay attention to the development and maintenance of the physical skills of dancers.

The results of the study confirmed the effectiveness of the author's program for the coordination skills development in future choreography teachers through jazzmodern dance. They also identified the need to improve the curriculum for the study of jazz-modern dance, the introduction of additional courses (disciplines chosen by students) to the program in the major "Choreography". It is recommended to consider the demand for highly qualified specialists in modern choreography. It is also necessary to increase the number of hours devoted to the study of jazz-modern dance. The technical and lexical base of jazz-modern dance in combination with special physical training provides opportunities for the coordination skills development in choreographers.

\section{Practical recommendations}

To improve the coordination skills of choreographers in the process of modern jazz dance studying, we offer the following practical recommendations. To include the following exercises into the process of training choreographers:

- Circuit training. Set of various motor tasks that exert a multifaceted effect on the body. These are exercises with a predominant focus on the formation of muscular feelings. For example, jumping crosswise (forward to the side, back - to the side), lunge back to "curtsy"; 15-20 repetitions - 3 times and 1.5 minutes of rest.

- "Mirror" exercises. Performance in pairs of separate elements, movements, combinations (students stand opposite each other - "mirror reflection"). The exercise duration is from 10 to 20 minutes. For example music size 2/4. Starting position: female students sit in a full squat in 6 poses; hands over the body; the arms barely touch the floor. $1 s t-2 n d$ bars - run around on the floor (left) with the left upper arm support on the floor. $\underline{3 r d}$ bar - step with the left foot to the side, left hand bent at the elbow, the right hand opens under the left hand, hands close at the same time as the body wave. $\underline{4 \text { th } \mathrm{bar}}$ 
- pas chaine to the 2nd point of the hall, jump, lunge with open hands.

- Exercises to develop flexibility. The required level of flexibility provides optimal amplitude, freedom, and efficiency of movements. Such exercises should be regular - at least 3-4 times a week. The technique should consider the individual, age, anatomical and physiological characteristics of dancers. We recommend keeping the following rules: class duration - at least $10 \mathrm{~min}$ and not more than 35-40 min; complexity increases gradually; the system of exercises ends with complete relaxation (duration from 5 to $10 \mathrm{~s}$ ).

- Exercises for stability and balance. Maintaining balance is an important condition for the quality performance of motor actions. To maintain a certain posture, it is recommended to increase the static stability of the body: performing motor tasks in light conditions; gradually move to more complex movements. For example a) training balance in the rack on one leg (bend the other back, arms at the waist); b) gradually complicate the program of action - training to maintain high stability of the body in a high position on the toes on a gymnastic bench, deck (with different positions of the arms, body and free leg). Increasing the stability of the body in dynamic exercises is much more difficult to achieve. This is due to the need to overcome a group of translational reflexes. We recommend performing: run exercises along one line; acceleration and a series of acrobatic jumps along a specially marked corridor (narrow line of 10-15 cm); completion of a series of acrobatic jumps with stable landing poses.

- Rhythmic exercises. When performing dance exercises, include motor actions with different tempos and rhythms. This will help applicants to determine their easily and quickly their rhythm. Performing the contrasting movements with an unexpected change in their direction, amplitude, tempo, speed, dynamics. This will make the overall scheme of motor action bright, expressive, spectacular, and attractive. considering the sets of exercises for all physical skills development and with an emphasis on the implementation of complex coordination exercises.

- Exercises to develop plasticity. Plasticity is characterized by movements performed together (without pauses, without a visible tension, with a smooth distribution of forces). To improve plasticity, it is recommended to form in students the skills of mentally creating motor actions: mentally reproduce several motor actions to avoid unjustified stops, pauses, sharp contrasting movements. The development and improvement of plasticity are more effective when acquainting students with the basic requirements of choreographic composition: slow start; in the middle of the composition there is an increase in effort, culmination; the end of the motor task is indicated by a fixed pose.

\section{Conflict of interest.}

The authors declare no conflict of interest.

\section{References}

1. Modern dance technique language / terminology [Internet]. 2021 [updated 2021 Jun 01; cited 2021 Jun 25]. Available from: https://www.stolaf.edu/depts/dance/faculty/anthony/ courses/Modern-Dance-Language.htm

2. Bernstein NA. The co-ordination and regulation of movements. Oxford, New York, Pergamon Press; 1967.

3. Matveev LP. Theory and methods of physical culture. Moscow: Physical culture and sport; 2008. (In Russian).

4. Logan SW, Ross SM, Chee K, Stodden DF, Robinson LE. Fundamental motor skills: A systematic review of terminology. Journal of Sports Sciences. 2018;36(7):781-796. https://doi.org/10.1080/02640414.2017.1340660

5. Marchenko S, Bezpalko D. Control and Assessment of 7-Year-Old Boys' Coordination Abilities at the Initial Training Stage in Kyokushin Karate. Journal of Learning Theory and Methodology, 2020;1:82-8. https://doi.org/10.17309/j1tm.2020.2.06

6. Boutios S, Fiorilli G, Buonsenso A, Daniilidis P, Centorbi $M$, Intrieri $M$, et al. The Impact of Age, Gender and Technical Experience on Three Motor Coordination Skills in Children Practicing Taekwondo. International Journal of Environmental Research and Public Health. 2021;18(11). https://doi.org/10.3390/ijerph18115998

7. Solovey O, Hunchenko V, Solovey D, Wnorowski K. Influence of static balances level on competitive performance indicators of athletes 17-21 years old in beach volleyball. Physical Education of Students. 2020;24(6):332-9. https://doi.org/10.15561/20755279.2020.0605
8. Hermassi S, Fadhloun M, Chelly MS, Bensbaa A. Relationship between agility T-test and physical fitness measures as indicators of performance in elite adolescent handball players. Pedagogics, Psychology, MedicalBiological Problems of Physical Training and Sports. 2011;5:125-131.

9. Barylko MG. Comparative Overview of Functional and Motor Preparedness of First- and Second-Year College Students. Teoriâ Ta Metodika Fìzičnogo Vihovannâ, 2019;19:14-22. https://doi.org/10.17309/tmfv.2019.1.02

10.Chien KP, Chen S. The Influence of Guided Error-Based Learning on Motor Skills Self-Efficacy and Achievement. Journal of Motor Behavior. 2018;50(3):275-284. https://doi.org/10.1080/00222895.2017.1341377

11.Limanskaya O, Kriventsova I, Podrigalo L, Yefimova O, JagielloM. The influence of professional training disciplines on the physical fitness level of the folk dance department students. Pedagogy of Physical Culture and Sports. 2020;24(5):248-54. https://doi.org/10.15561/26649837.2020.0505

12.Nyberg G, Meckbach J. Exergames "as a teacher' of movement education: exploring knowing in moving when playing dance games in physical education. Physical Education and Sport Pedagogy. 2017;22(1):1-14. https://doi.org/10.1080/17408989.2015.1112778

13.Vaganova V. Basics of classical dance. St. Petersburg; 2000. (In Russian).

14.Hua W. Research on the special training model of sports dance based on flexibility and coordination. Agro Food Industry Hi-Tech. 2017;28(3):981-985. 
15.Busol A, Busol V, Kronshtal' G, Cibul's'kij M. Stage movement as a part of professional training of students majoring in physical acting. Fizichna kul'tura, sport ta zdorov'ia nacii, 2014; 17: 34-41. (In Ukrainian).

16.Ou Tsin. Development of coordination skills of masters in the process of studying the dance style "contemporary". In: Current issues of contemporary art education in the context of European integration: choreographic art, April 12, 2020. Kharkiv: KhNPU; 2020. P. 85-89.

17.Agopyan A. An analysis of movements with or without back bend of the trunk or large hip extension in 1(st) Juniors' Rhythmic Gymnastics World Championship-2019. Is there injury risk for gymnasts? International Journal of Performance Analysis in Sport. 2021;21(1):108-125. https://doi.org/10.1080/24748668.2020.1850038

18. Sierra-Palmeiro E, Bobo-Arce M, Fernandez-Villarino M, Alonso-Tajes F, Gonzalez-Martin MC, Gomez-Rivas L. Association foot morphology and performance in rhythmic gymnastics. Revista Internacional De Medicina Y Ciencias De La Actividad Fisica Y Del Deporte. 2020;20(79):567-583. https://doi.org/10.15366/rimcafd2020.79.012

19. Orbaek T, Engelsrud G. Teaching creative dance in school - a case study from physical education in Norway. Res Danc Educ. 2020;15. https://doi.org/10.1080/14647893.2020.1798396

20.Neville RD, Makopoulou K. Effect of a six-week dancebased physical education intervention on primary school children's creativity: A pilot study. European Physical Education Review. 2021;27(1):203-220. https://doi.org/10.1177/1356336x20939586

21.Amado D, Molero P, Del Villar F, Tapia-Serrano MA, SanchezMiguel PA. Implementing a Teacher-Focused Intervention in Physical Education to Increase Pupils' Motivation towards Dance at School. Sustainability. 2020;12(11):13. https://doi.org/10.3390/su12114550

22.Mattsson T, Larsson H. 'There is no right or wrong way': exploring expressive dance assignments in physical education.
PhysicalEducationand SportPedagogy.2021;26(2):123-136. https://doi.org/10.1080/17408989.2020.1752649

23. Ward G, Scott D. Lived experiences of undergraduate physical education students studying gymnastics and dance education. Sport Education and Society. 2020;25(2):213-229. https://doi.org/10.1080/13573322.2019.1571485

24.Gibbs B, Quennerstedt M, Larsson H. Teaching dance in physical education using exergames. European Physical Education Review. 2017;23(2):237-256. https://doi.org/10.1177/1356336x16645611

25.Marquis JM, Metzler M. Curricular Space Allocated for Dance Content in Physical Education Teacher Education Programs: A Literature Review. Quest. 2017;69(3):384-400. https://doi.org/10.1080/00336297.2016.1256223

26.World Medical Association Declaration of Helsinki: Ethical Principles for Medical Research Involving Human Subjects. JAMA, 2013;310:2191. https://doi.org/10.1001/jama.2013.281053

27.Bondrevskij E.Ia. Age features of the development of balance functions in schoolchildren. In: Kuznecova ZI (ed.). Motor skill development of school children. Moscow: Enlightenment; 1987. (In Russian).

28.Kolumbet OM. Coordination skills development. Kiev: Education of Ukraine; 2014. (In Ukrainian).

29. Slapsys R. International Dictionary of Modern Dance. Reference \& User Services Quarterly, 1999;38(4): 418.

30.Jadranka Vlašić, Goran Oreb, Damir Vučić. Basic motor abilities and dancing efficiency of the female students at faculty of kinesiology in Zagreb. 8th International Scientific Conference on Kinesiology. Opatija, Croatia. 2017. P. 829833.

31.Srhoj Ljerka, Ratko Kati, Andreja Kaliterna. Motor Abilitiesin Dance Structure Performance in Female Students. Original scientific paper, 2006; 2: 335-341.

32.Nikitin VIu. Modern-jazz dance: Stages of development. Methodology. Technique. Moscow: Publishing house "One of the best"; 2004. (In Russian).

\section{Information about the authors:}

Olga V. Limanskaya; PhD (Art History), Associate Professor; http://orcid.org/0000-0002-4968-7515; olgalymanska@gmail. com; H.S. Skovoroda Kharkiv National Pedagogical University; Kharkiv, Ukraine.

Olena V. Yefimova; PhD (Pedagogical Sciences); https://orcid.org/0000-0001-5532-7324; halaburdina_e@ukr.net; H.S. Skovoroda Kharkiv National Pedagogical University; Kharkiv, Ukraine.

Irina V. Kriventsova; (Corresponding author); $\mathrm{PhD}$ (Pedagogical Sciences), Associate Professor, Head of the of Martial Arts Department; http://orcid.org/0000-0001-6931-3978; kriventsova.ira@ukr.net; H.S. Skovoroda Kharkiv National Pedagogical University; Kharkiv, Ukraine.

Krzysztof Wnorowski; PhD; https://orcid.org/0000-0001-5505-7985; krzysztof.wnorowski@awf.gda.pl; Department of Sports, Gdansk University of Physical Education and Sport; Gdansk, Poland.

Abdelkrim Bensbaa; PhD (Physical Education and Sport), Scientific researcher; https://orcid.org/0000-0002-0931-1847; benleone@gmail.com; Military Center of Sport Training; Abu Dhabi, United Arab Emirates.

\section{Cite this article as:}

Limanskaya OV, Yefimova OV, Kriventsova IV, Wnorowski K, Bensbaa A. The coordination abilities development in female students based on dance exercises. Physical Education of Students, 2021;25(4):249-256.

https://doi.org/10.15561/20755279.2021.0406

This is an Open Access article distributed under the terms of the Creative Commons Attribution License, which permits unrestricted use, distribution, and reproduction in any medium, provided the original work is properly cited http://creativecommons.org/licenses/by/4.0/deed.en 